\title{
RANCANG BANGUN ALAT UKUR SUHU BAWAH PERMUKAAN BUMI MENGGUNAKAN IC SENSOR LM35 UNTUK PENGUKURAN SECARA MAPPING
}

\author{
Gribel Gerald Tumiwan ${ }^{1)}$, Verna Albert Suoth ${ }^{1)}$, As'ari $^{1)}$ \\ ${ }^{1)}$ Program Studi Fisika, FMIPA UNSRAT \\ e-mail: gribelgerald@yahoo.com, vernasuoth@yahoo.co.id, as.ari2222@yahoo.co.id
}

\begin{abstract}
ABSTRAK
Telah dilakukan penelitian untuk mengembangkan alat ukur suhu bawah permukaan bumi secara mapping dengan menggunakan IC Sensor LM35DZ. Akuisisi data alat ukur bawah permukaan menggunakan sistem akuisisi data mikrokontroler AVR ATmega8 dalam unit slave yang sebelumnya telah dibuat dan diuji. Pengembangan dilakukan dengan menambah jumlah sensor menjadi 20 unit dan menghubungkan dengan sistem akuisisi data. Pengujian alat ukur suhu secara mapping dapat dilakukan dengan menyebar 20 sensor pada 20 titik berbeda. Hasil data yang telah direkam, dibuat menjadi peta suhu bawah permukaan melalui tampilan kontur mapping menggunakan program surfer. Hasilnya menunjukan bahwa alat ukur suhu bawah permukaan bumi memiliki kemampuan mendeteksi setiap perubahan suhu secara realtime pada 20 titik berbeda.
\end{abstract}

Kata Kunci: Alat ukur suhu, IC Sensor LM35DZ, mapping.

\section{DESIGINING AND CONSTUCTION EARTH'S SUBSURFACE TEMPERATURE MEASURING INSTRUMENT USING LM35 IC SENSOR FOR MAPPING MANNER MEASUREMENT}

\begin{abstract}
A research has been done to develop earth's subsurface temperature measuring instrument using LM35 IC sensor for mapping manner measurement. Data acquisition for the instrument used microcontroller AVR Atmega8 data acquisition system that the slave unit has been made and tested before. A development be done by added the sensor to be twenty units and connected it to acquisition data system. The testing for temperature measuring instrument in mapping manner could be done by spreading the twenty sensors to twenty different point. The data output that has been recorded, be made into earth's subsurface temperature map through contour mapping display used surfer program. The output showed that the earth's subsurface temperature measuring instrument could detect realtime temperature changing at twenty different point.
\end{abstract}

Keywords : Temperature measuring intrument, LM35DZ, mapping

\section{PENDAHULUAN}

Suhu bawah permukaan bumi memiliki nilai yang berbeda, tergantung pada beberapa faktor. Faktor-faktor tersebut antara lain anomali intensitas matahari, anomali panasbumi dan sebagainya (Mustofa, 2011). Suhu bawah permukaan banyak diamati untuk berbagai tujuan, antara lain kebutuhan pertanian dan survei pendahuluan dalam mengamati anomali panasbumi yang digunakan sebagai acuan untuk survei potensi panasbumi di daerah yang memiliki manifestasi panasbumi (Royana, 2013). Aspek penting dari sebuah peta sebaran suhu untuk sistem panas bumi pada suatu daerah akan menampakkan keberadaan sumber panas bumi tersebut. Agar diketahui sumber panas bumi, maka diperlukan suatu metode yang mempunyai kemampuan dalam mendeteksi sumber panas bumi (Suoth., dkk, 2012). 
Metode termal merupakan metode untuk mengamati pola aliran suhu bawah permukaan yang dapat di amati dengan cara mapping, dan menginterpretasikan model distribusi aliran suhu bawah permukaan. Selain itu dari segi pembiayaan penggunaan metode termal untuk mengukur suhu bawah permukaan, lebih murah dari metode ukur suhu lainnya (Hadi dan Refrizon, 2005). Menurut Gupta dan Roy (2007) pengukuran dengan metode termal dapat dilakukan pada kedalaman $\sim 1 \mathrm{~m}$. Pengukuran dengan metode termal dapat dilakukan dengan cara mapping yang kemudian pola aliran suhu diproses dengan suatu sistem terdistribusi (Hadi dan Refrizon, 2005). Distribusi suhu bawah permukaan dapat diketahui dengan melakukan pengukuran suhu pada kedalaman $1 \mathrm{~m}$ dari permukaan.

Sebelumnya oleh (Suoth., dkk, 2012) telah dibuat sebuah sistem akusisi data untuk survei panas bumi. Sistem instrumentasi yang telah dikembangkan mampu mengukur dan memonitor distribusi suhu bawah permukaan. Sistem yang dibangun berbasis jaringan sistem terdistribusi dengan topologi field-bus, menggunakan arsitektur single-master multislave dengan sistem akuisisi data berbasis mikrokontroler menggunakan AVR ATmega 8. Pada penelitian ini, dikembangkan rancang bangun alat pengukuran suhu bawah permukaan, untuk mengetahui anomali gradien suhu yang diakibatkan oleh intensitas matahari dan panasbumi dengan pengukuran secara mapping, dengan membuat 20 modul elektroda yang masing-masing mempunyai 1 IC sensor LM35.

\section{SISTEM INSTRUMENTASI}

Sistem instrumentasi terdiri dari empat bagian utama, yaitu:

1) Bagian sensor, berfungsi sebagai pendeteksi keadaan suhu bawah permukaan tanah.

2) Bagian Pengkondisi sinyal, sistem elektronika yang berfungsi mengkondisikan sinyal dari sensor agar sesuai dengan kebutuhan sinyal untuk mikrokontroler.

3) Bagian akuisisi data, berfungsi menkonversikan besaran fisis sumber data ke bentuk sinyal digital.

4) Penampil, berfungsi menampilkan data suhu yang telah dikonversi pada data digital. Penampil pada penelitian ini adalah monitor PC.

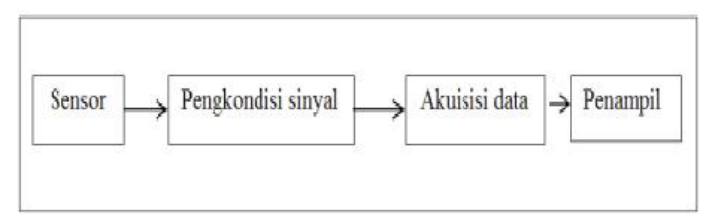

Gambar 1. Bagian utama perancangan sistem Instrumentasi (Suoth., dkk, 2012)

\section{Sensor Suhu}

Sensor Suhu adalah komponen yang biasanya digunakan untuk merubah panas menjadi listrik untuk mempermudah dalam menganalisa besarannya (Tumimomor, 2009). Sensor Suhu LM 35 yang dipakai dalam penelitian ini, berupa komponen elektronika yang diproduksi oleh National Semiconductor. Seri LM 35 merupakan sensor suhu yang akurat dan tegangan keluaran linear sebanding dengan suhu ${ }^{\circ}$ Celcius. LM 35 memiliki keuntungan lebih linier, memiliki impedansi keluaran yang rendah, keluaran linier, dan kalibrasi tepat, yang membuat antarmuka ke pembacaan atau sirkuit kontrol sangat mudah. Sumber tegangan bisa digunakan satu sumber tegangan, ataupun dengan sumber positif dan negatif. Jangkauan pengukuran dari pada LM 35 antara $-55^{\circ} \mathrm{C}$ sampai $150{ }^{\circ} \mathrm{C}$ suhu jangkauan (Yayavaram., dkk, 2009).

\section{Pengkondisi Sinyal}

Pengkondisi sinyal adalah rangkaian elektronik yang dirancang khusus sehingga dapat digunakan untuk penguatan, penyaringan (filter), dan lain-lain. Rangkaian pengkondisi sinyal digunakan oleh sensor secara langsung untuk memperoleh parameter fisik yang diubah menjadi sinyal keluaran ( Nurhasanah., dkk, 2009). Op-Amp (Operasional Amplifier) merupakan IC yang dapat dimanfaatkan untuk penguat tegangan. Amplifier noninverting dapat dikonstruksi seperti ditunjukkan dalam Gambar 2. Gain rangkaian ini dicari dengan menjumlahkan arus-arus pada summing point (S), dan menggunakan kenyataan bahwa tegangan summing point adalah $V_{\text {in }}$ sehingga tidak ada beda tegangan yang muncul melalui terminalterminal input (Roberge dan Lundberg, 2007). 


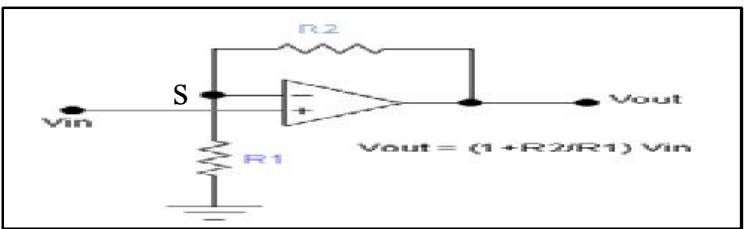

Gambar 2. Noninverting amplifier

Gain tegangan untuk noninverting akan di ketahui dengan:

Dengan :

$$
A v(\text { gain })=R 2 / R 1+1
$$

$R 2=$ resistor feedback $(\Omega)$, dan

$R 1=$ resistor $(\Omega)$.

\section{ADC (Analog to Digital Converter)}

ADC (Analog to Digital Converter) adalah suatu perangkat yang mengubah suatu data kontinu terhadap waktu (analog) menjadi suatu data diskrit terhadap waktu (digital).

Proses yang terjadi dalam ADC adalah:

1) Pencuplikan

2) Pengkuantisasian

3) Pengkodean

Secara matematis, proses ADC dapat dinyatakan dalam persamaan:

Data $A D C=\left(V_{\text {in }} / V_{\text {ref }}\right) \times$ Maksimal Data

Digital.

\section{SURVEI GRADIEN SUHU DALAM METODE GEOFISIKA}

Gradien suhu survei memberikan data dasar tentang suhu bawah permukaan dan sering digunakan sebagai kriteria utama dalam menentukan titik pengeboran. Survei pengukuran suhu menggunakan teknik termal dengan melakukan pengukuran pada kedalaman $1 \mathrm{~m}$ dan dapat di gunakan untuk mendeteksi anomali tempat yang panas. Ketika struktur geologi mengontrol aktivitas termal, pada bacaan tertentu penyelidikan 1 meter memiliki nilai yang sama dengan survei citra inframerah. Pengukuran dibuat bersama profil atau dalam pola grid pada jarak yang bervariasi dari 10 hingga $100 \mathrm{~m}$ (Gupta dan Roy, 2007).

\section{METODE DAN BAHAN}

Metodologi yang dilakukan pada penelitian ini meliputi studi literatur guna memperoleh informasi pada penelitianpenelitian sebelumnya dan mencari referensi pendukung dalam penelitian yang akan dilakukan. Langkah selanjutnya adalah mendesain dan merakit modul elektroda kemudian menghubungkan dengan sistem akuisisi data yang sudah di rancang oleh Suoth (2012) berupa modul slave mikrokontroler AVR ATmega8. Kemudian dilakukan pengujian dilaboratorium FMIPA UNSRAT, setelah dikalibrasi dengan termometer digital sebagai standar, dilakukan pengujian di jalan ringroad Manado.

Modul Slave dan Modul Master sebelumnya telah dibuat dan di uji oleh Suoth (2012), modul slave sebagai akuisisi data di tunjukan pada Gambar 3, dan modul master sebagai power supply di tunjukan oleh Gambar 4. Pembacaan keluaran oleh monitor pada PC.

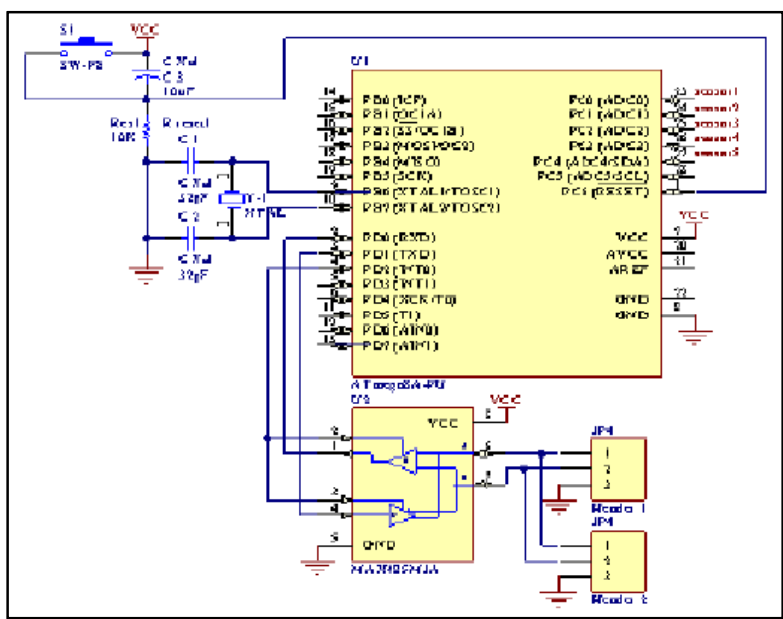

Gambar 3. Sistem minimum modul Slave AVR ATmega 8 yang digunakan

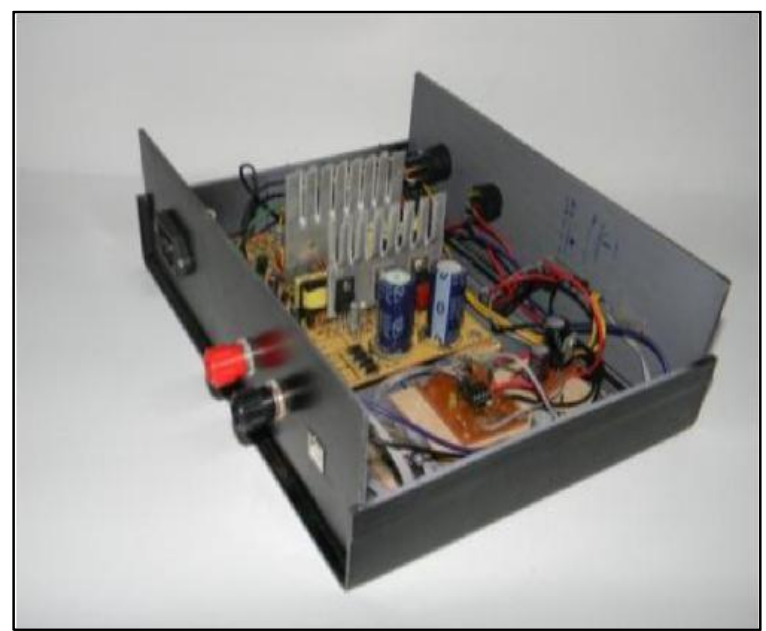

Gambar 4. Modul Power Supply Yang digunakan 


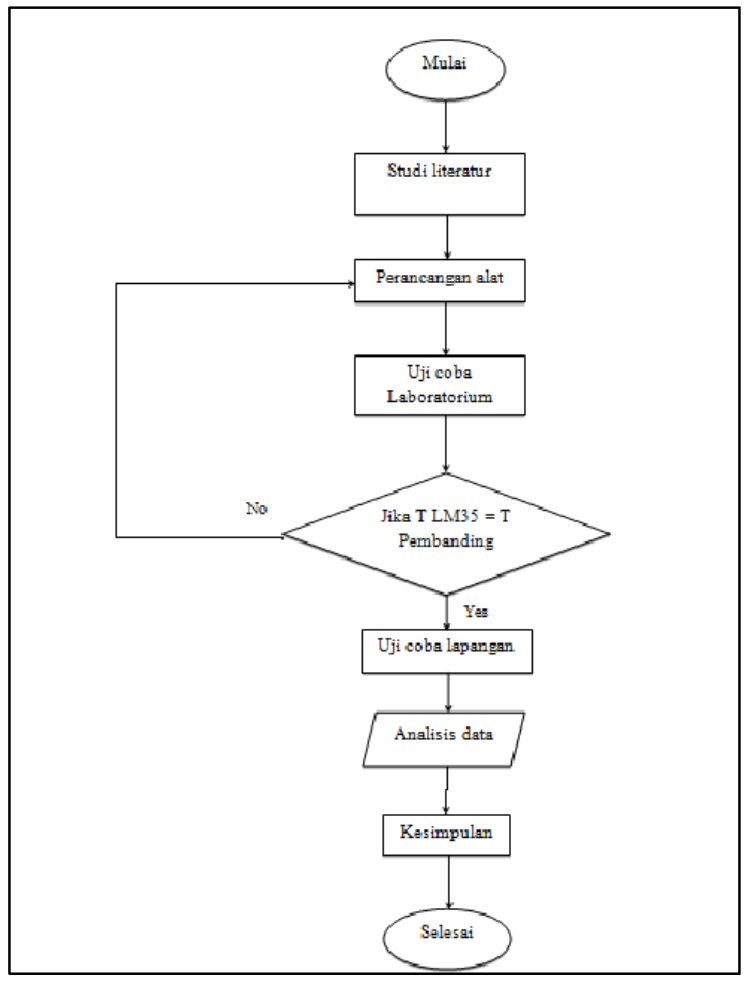

Gambar 5. Diagram alir penelitian

\section{HASIL DAN PEMBAHASAN}

\section{Rancangan Alat \\ Rancangan Elektroda}

Elektroda di rancang seperti pada Gambar 6. Terdiri dari 5 bagian terpisah yakni pipa besi, sock besi, elbow besi $90^{\circ}$, dop besi dan sensor LM35. Sensor suhu LM35 akan mendeteksi suhu secara langsung. Modul yang dirancang menggunakan pipa besi, dan bisa dimasukkan kebawah permukaan sedalam 1 meter. Sock besi ditempelkan sensor untuk mempermudah perakitan alat.

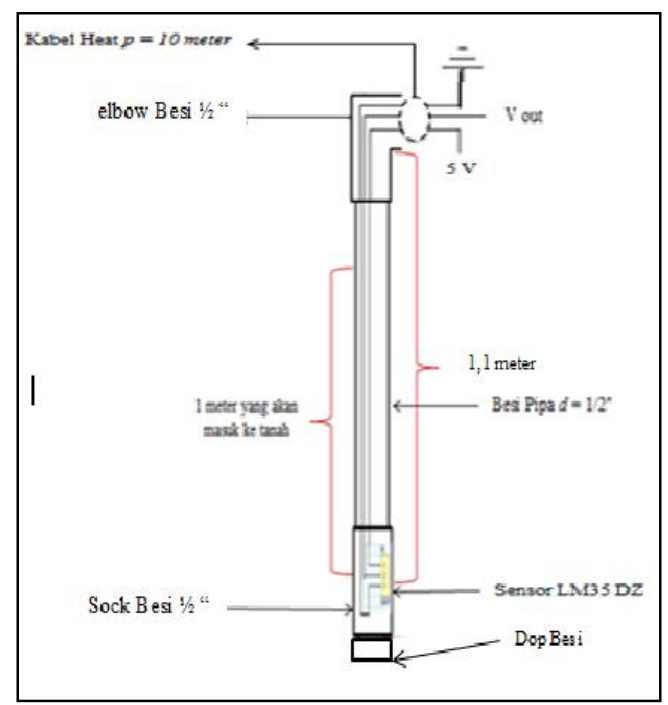

Gambar 6. rancangan Elektroda

\section{Perancangan Pengkondisi Sinyal}

Pengkondisi sinyal sebelumnya telah dirancang oleh Suoth (2012), seperti Gambar 7.

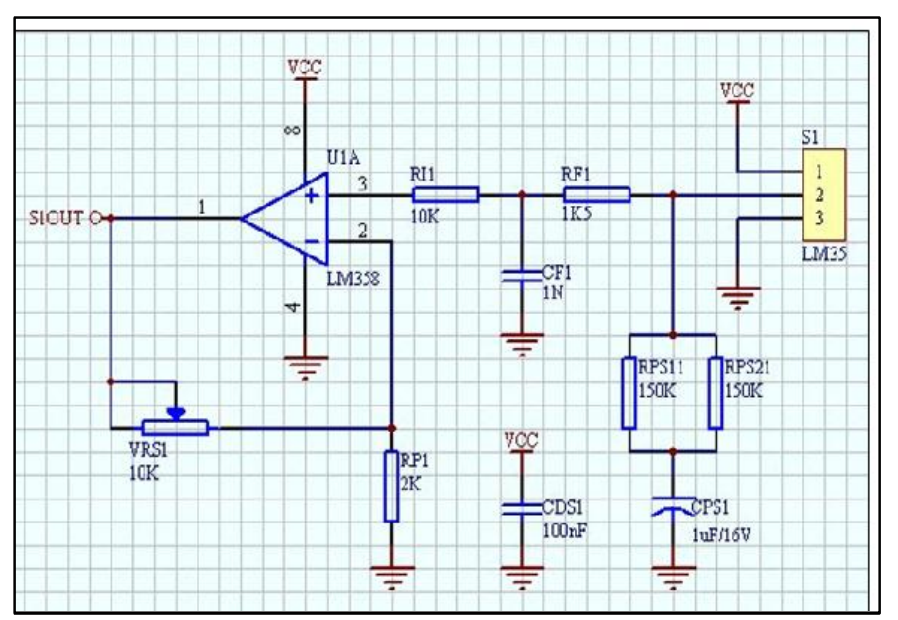

Gambar 7. Rancangan Pengkondisi sinyal yang digunakan

VRS1 (Variabel Resistor) Merupakan

Potensio $10 \mathrm{~K} \Omega$ yang berfungsi mengatur besar resistansi sehingga penguatannya sesuai kebutuhan pada sistem akuisisi data mikrokontroler AVR ATmega8.

\section{Perakitan Alat}

\section{Perakitan Elektroda}

Setelah semua terakit telah menjadi suatu bentuk utuh sebagai komponen elektroda seperti Gambar 8.

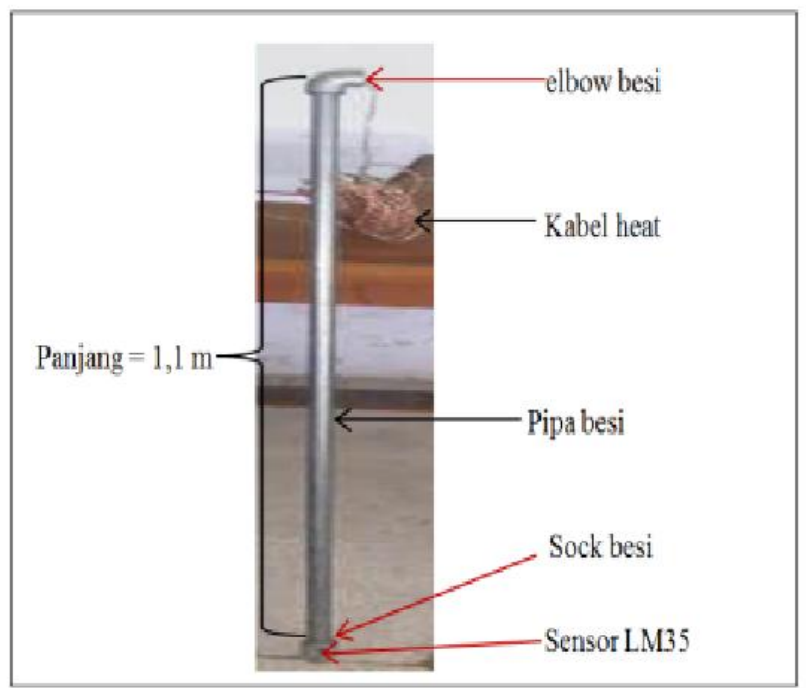

Gambar 8. Rakitan Elektroda utuh Setelah terakit seperti pada Gambar 8 elektroda siap untuk digunakan. Sensor suhu akan mendeteksi suhu (besaran fisis) dan mengirimnya menjadi data analog berupa 
tegangan (besaran listrik). Sensor yang terbuat dari bahan logam akan meningkat suhunya, yang menyebabkan terjadinya peningkatan hambatan yang membuat tegangan keluarannya sebanding dengan peningkatan pada hambatan. Sensor akan mendeteksi suhu secara langsung pada bagian yang bersentuhan, sehingga sensor tidak akan mengukur suhu pada besi. Sensor LM35 akan mendeteksi suhu melalui bagian ujung sensor. Rentang pengukuran rakitan ini adalah $0^{\circ} \mathrm{C}-100^{\circ} \mathrm{C}$ dan akan bekerja pada masukan tegangan 5 volt.

\section{Pengkondisi Sinyal}

Sinyal dari sensor suhu LM35 berupa sinyal analog akan diproses menjadi keluaran sinyal digital. Untuk dapat mengolah sinyal keluaran sensor dan menampilkan tiap perubahan suhunya, diperlukan ADC (analog to digital converter). Tegangan masukan yang dibutuhkan untuk memproses data menjadi data digital oleh ADC eksternal dalam mikrokontroler ATmega8 harus sesuai dengan resolusi dari ADC pada mikrokontroler ATmega8 dengan lebar data 8 bit.

Perubahan tiap $1{ }^{\circ} \mathrm{C}$ dari LM35 adalah $10 \mathrm{mV}$ dan ADC memiliki resolusi 1/255 yang di dapat dari $1 / 2^{\mathrm{n}}-1$, dimana $\mathrm{n}$ merupakan lebar data yaitu 8 bit. Penguat operasional dalam hal ini penguat tegangan, menjembatani perbedaan ini, sesuai dengan perhitungan:

\section{$V_{\text {in }} \times$ Resolusi $=$ tegangan yang dibutuhkan} mikrokontroler.

$$
5000 \mathrm{mV} \times 1 / 255=19,6 \mathrm{mV}
$$

Penguat operasional yang dibutuhkan =

$$
19,6 \mathrm{mV} / 10 \mathrm{mV}=1,96 \mathrm{kali}
$$

Dengan penguatan 1,96 kali oleh pengkondisi sinyal pada tegangan masukan $10 \mathrm{mV}$, ADC dapat pengolah sinyal LM35 untuk menampilkan perubahan tiap $1^{\circ} \mathrm{C}$. Setiap masukan pada pengkondisi sinyal harus dikuatkan 1,96 kali agar keluaran suhu dalam data digital dapat diproses oleh ADC. Hasil penguatan pengkondisi sinyal didapat dengan menggunakan persamaan untuk menentukan gain dari penguat non-inverting yaitu:

$$
G=1+R_{2} / R_{1}
$$

Tabel 1. Data uji masukan dan keluaran pada pengkondisi sinyal dan penguatan

\begin{tabular}{|c|c|c|}
\hline $\begin{array}{c}\text { Vin } \\
\text { (V) }\end{array}$ & $\begin{array}{c}\text { Vout } \\
\text { (V) }\end{array}$ & $\begin{array}{c}\text { Av } \\
\text { (Gain) }\end{array}$ \\
\hline 0,278 & 0,556 & 2 \\
\hline 0,288 & 0,576 & 2 \\
\hline 0,296 & 0,592 & 2 \\
\hline 0,344 & 0,688 & 2 \\
\hline 0,432 & 0,864 & 2 \\
\hline 0,535 & 1,07 & 2 \\
\hline 0,629 & 1,258 & 2 \\
\hline 0,708 & 1,416 & 2 \\
\hline 0,767 & 1,534 & 2 \\
\hline 0,811 & 1,622 & 2 \\
\hline
\end{tabular}

\section{Pengujian ADC}

Pengujian dilakukan dengan cara memberi tegangan masukan pada ADC dan mencatat data digital keluaran yang dihasilkan. Tegangan masukan pada ADC merupakan tegangan keluaran dari pengkondisi sinyal. ADC diperlukan dalam aplikasi mikrokontroler karena masukan dari mikrokontroler berupa data digital dan bukan data analog oleh karena itu diperlukan rangkaian $\mathrm{ADC}$. $\mathrm{ADC}$ ini sendiri sudah ada di dalam ATMega8. Karena di dalam mikrokontroller Atmega 8 sudah terdapat ADC ( analog digital converter) dengan lebar data 8 bit, maka tegangan yang telah dikuatkan, langsung dimasukan ke ADC dalam mikrokontroler dan hasil keluarannya telah dirancang sebelumnya oleh Suoth (2012) merupakan data suhu dalam ${ }^{\circ} \mathrm{C}$ :

$$
\begin{aligned}
& \text { Suhu }= \\
& \left(\frac{V_{\text {in }}}{V_{\text {ref }}}\right) \times \text { maksimum data digital..... } \\
& \text { Suhu }=\left(\frac{V_{\text {in }}}{5000 \mathrm{mV}}\right) \times 255
\end{aligned}
$$

Data pengujian pada Tabel 2 menunjukan selisih pengukuran pada 10 masukan (keluaran Op-Amp) tegangan yang berbeda. Selisih memperlihatkan semakin tinggi suhu, perbedaan suhu yang didapatkan semakin meningkat, namun selisi yang didapat sangat kecil sehingga data dari sensor LM35 bisa digunakan. $\mathrm{V}_{\text {ref }}$ sebesar $5000 \mathrm{mV}$ yang digunakan merupakan tegangan kerja pada mikrokontroler. Peneliti menggunakan alat ukur termometer digital yang sudah dikalibrasi sebagai pembanding. 
Tabel 2. Data hasil pengujian ADC adalah:

\begin{tabular}{|c|c|c|c|c|}
\hline $\begin{array}{c}V_{\text {ref }} \\
(\mathrm{mV})\end{array}$ & $\begin{array}{l}V_{\text {out }} \\
\text { Op- } \\
\text { Am } \\
p= \\
\mathbf{V}_{\text {in }} \\
\text { (m } \\
\text { V) }\end{array}$ & $\begin{array}{c}\text { Suhu } \\
\text { Keluar } \\
\text { an } \\
\text { ADC } \\
\left({ }^{\circ} \mathrm{C}\right)\end{array}$ & $\begin{array}{l}\text { Termomet } \\
\text { er Digital } \\
\left({ }^{\circ} \mathrm{C}\right)\end{array}$ & $\begin{array}{c}\text { Selisi } \\
\text { h } \\
\left({ }^{\circ} \mathbf{C}\right)\end{array}$ \\
\hline 5000 & 556 & 28,356 & 27,8 & 0,556 \\
\hline 5000 & 688 & 35,088 & 34,4 & 0,688 \\
\hline 5000 & 864 & 44,064 & 43,2 & 0,864 \\
\hline 5000 & $\begin{array}{c}107 \\
0\end{array}$ & 54,57 & 53,5 & 1,07 \\
\hline 5000 & $\begin{array}{c}125 \\
8\end{array}$ & 64,158 & 62,9 & 1,258 \\
\hline 5000 & $\begin{array}{c}141 \\
6\end{array}$ & 72,216 & 70,8 & 1,416 \\
\hline 5000 & $\begin{array}{c}162 \\
2\end{array}$ & 82,722 & 81,1 & 1,622 \\
\hline 5000 & $\begin{array}{c}172 \\
8\end{array}$ & 88,128 & 86,4 & 1,728 \\
\hline 5000 & $\begin{array}{c}178 \\
2\end{array}$ & 90,882 & 89,1 & 1,782 \\
\hline 5000 & $\begin{array}{c}180 \\
0\end{array}$ & 91,8 & 90 & 1,8 \\
\hline
\end{tabular}

Error $=$

selisih suhu pengukuran

$\frac{\text { selisih suhu pengukuran }}{\text { rata-rata suhu bacaan termometer digital }} \times 100 \%$ ..(7)

Error $=\left(65,2^{\circ} \mathrm{C}-63,9^{\circ} \mathrm{C}\right) / 63,9^{\circ} \mathrm{Cx}$ $100 \%$

Error $=2,03 \%$

Berdasarkan hasil pengamatan, selisih pembacaan nilai suhu rata-rata antara keluaran ADC dengan kalibrator hanya $2,03 \%$, selisih pembacaan rata-rata temperatur $\pm 1,3^{\circ} \mathrm{C}$. Besarnya error dapat dipengaruhi oleh penguatan pada pengkondisi sinyal dengan gain yang mengalami penguatan 2 kali.

\section{Pengujian Alat Ukur di Lapangan}

Pengujian alat di lapangan dilakukan di jalan ringroad Manado dengan mengambil daerah seluas 8 meter $\times 6$ meter Sensor disebar menjadi 4 lintasan, masing-masing lintasan memiliki 5 sensor dengan jarak antara masing-masing sensor 2 meter (Gambar 9).
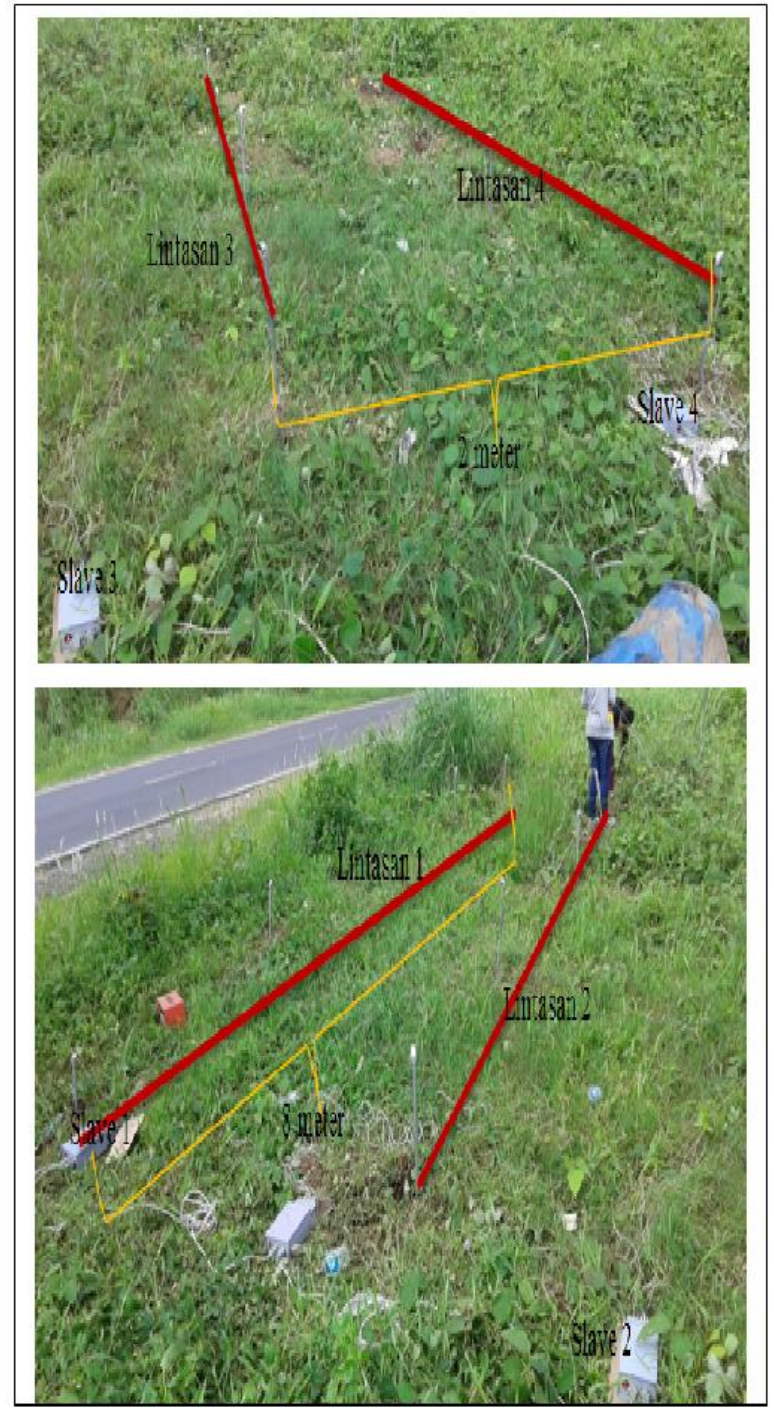

Gambar 9. Sebaran Elektroda pada saat pengujian lapangan

Data yang terekam kemudian diolah dan ditampilkan dengan tampilan peta kontur mapping pada Gambar 10 melalui sofware surfer. Sumbu x merupakan koordinat lintang utara dan sumbu y menunjukan koordinat bujur timur. Perubahan suhu dapat dilihat dengan perubahan warna yang terjadi setiap 30 menit. 


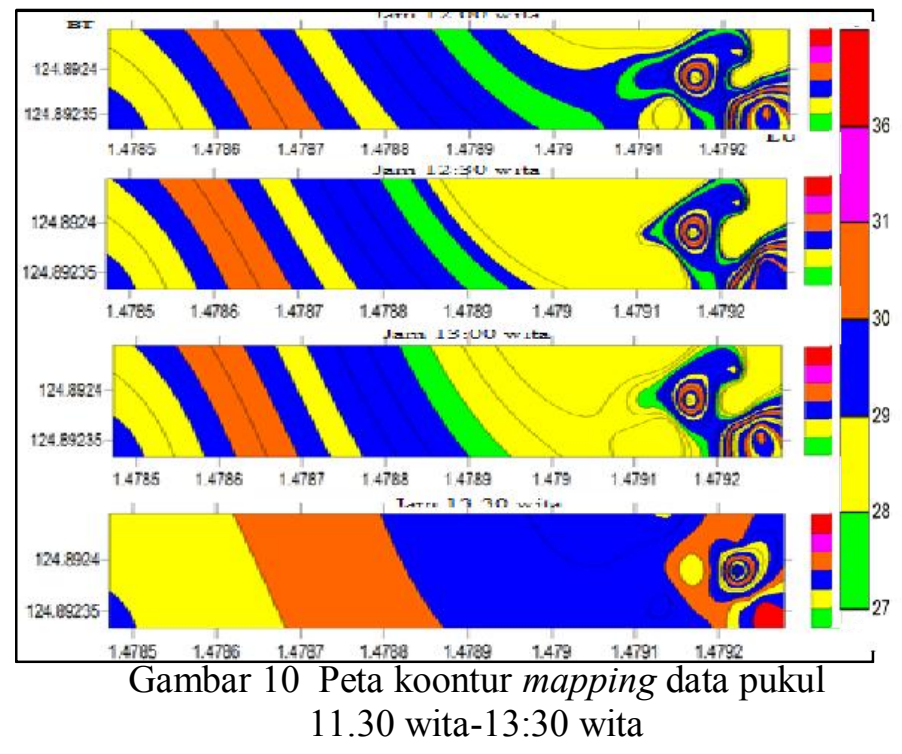

Dari Gambar 10 menunjukan perubahan suhu yang ditunjukan dengan perubahan warna pada peta kontur setiap 30 menit. Pengukuran pada kedalaman 1 meter yang dilakukan dijalan ringroad masih sangat dipengaruhi oleh intensitas matahari. Terlihat dari cuaca saat pengujian yang mendung (berawan) menunjukan bahwa suhu bawah permukaan pada daerah pengujiian terukur antara $27^{\circ} \mathrm{C}-36^{\circ} \mathrm{C}$. Ini bisa disebabkan oleh objek bawah permukaan yang diukur merupakan tanah timbunan dan daerah pengukuran yang pada beberapa titik terhalagi oleh pohon. Penggunaan alat akan sangat maksimal pada daerah yang tidak terhalangi oleh pohon dan akan menghasilkan tampilan kontur yang baik jika dilakukan pada daerah yang struktur bawah permukaannya sudah tersusun sejak lama.

\section{KESIMPULAN}

Telah berhasil dirancang dan dibangun alat pengukur suhu bawah permukaan bumi dengan menggunakan IC Sensor LM35 dengan interpretasi data secara mapping hasil sebaran suhu pada 20 titik dengan kedalaman 1 meter. Alat ukur suhu yang dibangun telah dapat digunakan mendeteksi perubahan suhu bawah permukaan dengan akurasi yang baik.

\section{DAFTAR PUSTAKA}

Gupta, H., and S. Roy. 2007. Geothermal Energy An Alternative Resource for the 21st Century. Elsevier, Amsterdam.

Hadi, A.I., Refrizon, 2005. Distribusi sumber panas bumi berdasarkan survei gradien suhu dekat permukaan gunung api Hulu Lais. Jurnal Gradien. Jurusan Fisika. Universitas Bengkulu. Bengkulu. 1 (2): 64-68

Mustofa. 2011. Meteorologi dan klimatologi. Jurusan STKIP PGRI. Pontianak.

Nurhasanah, M. Melania S.M., dan Y. D. Hapsari. 2009. Optimasi Sistem Pengukuran Melalui Modifikasi Pengkondisi Sinyal Pada Sensor Gas Co. Jurusan Fisika . ITS, Surabaya.

Roberge J.K., and K. H. Lundberg. 2007. Operational Amplifiers: Theory and Practice Second Edition. Massachusetts Institute of Technology. Massachusetts, United States.

Royana, R. 2013. Panduan Kelestarian Ekosistem untuk Pemanfaatan Panas Bumi. WWF-Indonesia.

Suoth, V.A., Santoso, D.R., dan S. Maryanto. 2012. Pengembangan Array sensor Suhu dan Sistem Akusisi Data Berbasis Mikrokontroler untuk Pengukuran Suhu Bawah Permukaan. Jurnal Mipa Unsrat Online. 2 (1): 66-72

Tumimomor, F. 2009. Perancangan Sistem Pengontrol Suhu Ruang Berbasis Mikrokontroler 89C51. Jurusan Fisika. [Skripsi] UNSRAT, Manado.

Yayavaram, N.M., Saritha, C., dan S. Velamakuri. 2009. Embedded Processor Based Automatic Temperature Control of VLSI Chips. Department of Electronics, S.S.B.N. College (Autonomous), Anantapur, A.P. India. Sensors \& Transducers Journal. 100. (1): 27-44 